\title{
Exploring the Role of Translation Studies in the Promotion of Chinese Culture Abroad: An Interdisciplinary Perspective
}

\author{
Tao Yang, * \\ ${ }^{1}$ School of English Studies, Xi'an International Studies University, Xi'an, 710128, China \\ *Corresponding author: Tao Yang (Email: yangtao@xisu.edu.cn)
}

\begin{abstract}
Since the reform and opening up, China's comprehensive national strength and international status have been continuously enhanced. Compared with its economic achievements, however, China has a disproportionate discourse power in international communities. Consequently, it becomes a top priority for the country to further strengthen its international communication and elaborately construct an external discourse system to meet the national strategy of telling China's stories well and making China's voice heard. As an important medium of communication, translation studies should be integrated with intercultural communication studies in response to the urgent issue: How to effectively translate China and enhance its external discourse power in the world. From an interdisciplinary perspective, this article proposed that the boundaries of translation studies should be expanded to integrate correlated research domains including external discourse studies, intercultural communication studies, and national translation studies for the sake of exploring effective paths for the promotion of Chinese culture abroad.
\end{abstract}

Keywords: External Discourse, Intercultural Communication, National Translation Studies, Translation and Communication Studies.

\section{Introduction}

China has become the world's second largest economy, playing an increasingly important role in international communities and assuming pivotal responsibilities. However, China's external discourse power in the world is inconsistent with its economic development. To address this urgent issue, Chinese President Xi Jinping stressed that it is necessary to deeply understand the importance and necessity of strengthening and improving the work of international promotion under the new circumstances, continuously strive to enhance the capacity for China's engagement in international communication, and establish an international discourse power that matches the country's comprehensive national strength and international status. In addition, it is crucial to create an external public opinion environment that is conducive to the reform, development and stability of China on the one hand, and make positive contributions to construct a human community with a shared future on the other hand.

To eliminate the barriers between different cultures and reduce the misunderstandings caused by different languages, it is essential to exchange discourse appropriately between different cultural backgrounds in international communication. In the process of discourse exchange, the importance of translation is self-evident. Therefore, translation, once invisible behind the scenes of cultural communication activities, has turned into an important processor and producer of cultural symbols and a new medium for promotion of Chinese culture abroad.

In the context of the new era, translation studies in China should establish cultural confidence, theoretical confidence, and discourse confidence, and colleagues of translation studies should strive to find ways to strengthen the capacity for international communication and enhance the international influence of China's external discourse so as to tell China's stories well and make China's voice heard. In order to explore effective paths for the international communication of China's discourse, the boundaries of translation studies should thereby be expanded to integrate correlated research domains including external discourse studies, intercultural communication studies, and national translation studies from the perspective of interdisciplinary integration.

\section{External Discourse in Translation Studies}

The new era puts forward higher requirements for the discipline of translation. Colleagues of translation studies, under the new circumstances, should not only pay attention to translation theory and practice, but also take the initiative to shoulder the critical task of serving the national strategy: to promote Chinese culture abroad, to tell China's stories well, and to make China's voice heard. Translation, in essence, is a process of discourse construction that demonstrates and moulds images. Images, whether between the source text and the target text, or between the source language culture and target language culture, are all closely related to translation practice. [1] Therefore, it is a pivotal mission for colleagues of translation studies to explore ways to effectively translate China in order to inspire and influence the international audience, strengthen China's discourse power in the world arena, and enhance the soft power of Chinese culture in international communities.

Judging from the theoretical construction of the discipline and translation practice, it is evident that the purpose of translation studies is to achieve both interlingual communication and intercultural communication. Determined by this innate character, the ideological attribute of translation is far greater than its disciplinary attribute. It is 
argued by some scholars that in the development of translation discipline, the first turn of translation studies was towards linguistics, the second one towards culture, and the third towards discourse. [2]

Discourse not only shapes people's knowledge and thoughts, but also constructs social power and order. Therefore, to tell China's stories well and make China's voice heard, external discourse system (EDS) should be elaborately constructed in translation studies to enhance its creativity and credibility. Whether the external discourse with Chinese characteristics can be universally recognized by international communities ultimately depends on whether we have our say in the world and whether we have a powerful system of external discourse. [3] In other words, winning international discourse power depends not only on the country's comprehensive national strength, but also on the choice of epistemology and methodology in the process of China's discourse translation and dissemination, particularly the combined forces of various discourse variables with translation practice in this process.

External discourse is a country's self-statement towards the outside world. During the construction of EDS in translation studies, particular attention should be paid to the selection of topics. Presenting a true, multi-dimensional, and panoramic view of China to the world requires a discourse system that is in accordance with its rapidly rising international status, the key of which lies in the construction of a set of EDS with Chinese characteristics that can be understood and accepted by international communities. [4] Therefore, translation of external discourse with Chinese characteristics should be based on the dual needs of China and the target country with a different culture. This kind of translation practice, which ideally meets the needs of reciprocal cultural systems, can not only avoid unidirectional output of wishful thinking, but also promote multifaceted cooperation and interaction with the target cultural system. [1] To this end, ensuing in-depth research on the academic experience and practical issues of external discourse studies should be conducted to optimize the theoretical framework of translation studies, which, in turn, will facilitate the construction of an EDS with Chinese characteristics that is conducive to the promotion of Chinese culture abroad.

\section{Intercultural Communication in Translation Studies}

In the context of cultural globalization, intercultural communication becomes a concrete manifestation of the level of international exchanges and the construction of a humanistic environment in a specific country or region. From a disciplinary perspective, the connotation of intercultural communication not only involves linguistic factors such as language contact, language history, language development, language communication, language acceptance, speech adjustment, translation theory and practice, etc., but also pays close attention to the integration of culture and communication process, the interpretation of cultural differences, the identification of cultural interaction, and the production of cultural information. Intercultural communication not only studies the characteristics and patterns of interaction between individuals, groups, organizations, and countries under different cultural backgrounds, but also involves the interpretation and understanding of meanings between different cultures, concerning differences in culture and national psychology, cultural shock and cultural adaptation, the continuation and changes of culture, and the independence and development of national culture.

The international dissemination of China's stories inevitably involves intercultural communication. Researchers of translation studies should pay particular attention to the problems emerging in the process of intercultural communication so as not to affect the effect of dissemination. One of the most obvious problems in intercultural communication is misinterpretation, which refers to the inaccurate understanding and evaluation of one culture under the context of another culture. Different ideologies, different cultural backgrounds, especially inappropriate translation are all causes of misinterpretations in intercultural communication.

Misinterpretation, regardless of its causes, will have a negative impact on telling China's stories well. Therefore, Chinese President Xi Jinping stressed that it is necessary to improve the art of international communication by enhancing the theoretical research of international communication and mastering the principles of international communication. Furthermore, it is also essential to adopt precise communication approaches that are acceptable to different regions, countries, and groups of audience. Therefore, scholars and practitioners of international communication and translation studies should strive to promote the global, regional, and stratified expression of China's stories and China's voice, and consequently enhance the affinity and effectiveness of international communication. Through translation activities, intercultural communication continuously intensifies its power and attains precision in dissemination of external discourse.

From the perspective of communication, human is the sum of communication relations. The relationship between "I" and the "other" is not the same as the relationship between the communication subject and the communication object, but instead, they are two subjects coexisting in the same communication activity. [5] The subject-object thinking mode is misleading in that it regards the communication activity as a unidirectional process in which the communication subject transmits information to the object in order to exert a certain influence. As the transmitter of information in intercultural communication activities, the translator not only plays a crucial role in restoring and reconstructing the meaning of source text, but also bears the responsibility of disseminating cultural knowledge beneath the text. The interactive flow of knowledge among source text, translator, target text, and target readers demonstrates that there is an internal connection between translation and communication.

Translation practice in intercultural communication activities is no longer a simple conversion of words or concepts; instead, it becomes an organic component of intercultural communication activities and a powerful accelerator of cultural communication. In other words, translation and communication become twin sisters. Their innate isomorphism and interactivity give birth to Translation and Communication Studies (TCS) in the context of the newera liberal arts education in China. [2] Translation studies is essentially an open discipline with broad boundaries, which provides us with the possibility to understand and interpret TCS.

However, the construction of the TCS theory at home and abroad is still in the exploratory stage, and a systematic and 
persuasive discipline system has not yet been formulated. With the help of translation practice, intercultural communication is becoming an open and multi-dimensional cultural platform evolving from extensive development to indepth development for the international communication of Chinese culture. Therefore, research paradigm should be constructed by integrating translation studies with intercultural communication studies in a modern academic perspective.

\section{National Translation Studies and Practice}

Human culture, on the one hand, is unique and the combination of uniqueness constitutes the diversity of world culture. On the other hand, human culture also has some common features, and thus can transcend the geographical, national and historical boundaries to form a cultural community, within which each culture has its unique and inseparable position. It is the uniqueness and commonality that continuously push the development and renewal of world culture forward. National Translation Practice (NTP), an important translation concept initiated and proposed by Chinese scholars in recent years, emphasizes the uniqueness and commonality of each culture as well as China's own cultural position in the multicultural world so as to gain cultural awareness and cultural confidence.

NTP is a new concept in contemporary translation studies that integrates multiple disciplines and is a theoretical innovation and exploration carried out by Chinese academia in response to the current construction of China's EDS and the enhancement of national translation capabilities. [6] It is advocated by some scholars $[2,6,7]$ that NTP should be established as a legitimate branch of translation studies in China, which aims to enhance national translation capabilities and discourse skills and facilitate international communication of national translation in order to promote the cultural image of China. NTP, conducted under the auspices of national institutions, is conducive to navigating ideology and value orientation and excavating the cultural essence with both Chinese characteristics and common values of mankind.

The concept of NTP was put forward as a consequence of Chinese scholars' understanding of the "nationality" of translation. [7] NTP theory has its own theoretical and practical issues that should be immediately addressed. On the one hand, researches can be conducted in theoretical level including the definition of concepts, the description and induction of distinctive features. On the other hand, In-depth exploration can be made in practical level such as the relation between NTP and EDS, the relationship between NTP and the construction of national image, and also the relationship between NTP and intercultural communication. It is noteworthy that the study of NTP and the construction of external discourse system have brought NTP from the practical work of state bureaus and translation departments to the platform of academic research, which is of great significance at the present time.

In recent years, the emerging discipline National Translation Studies, which takes NTP as its research focus, is proposed by Chinese scholars to study and reveal the rules of national translation theory and practice, namely, the subject, behavior, phenomenon, mechanism, policy, acceptance, influence and methods of national translation. [2] In other words, National Translation Studies strives to reveal the rules of national translation theory and practice. In the context of the great rejuvenation of the Chinese nation, the scale of NTP is gradually expanding with China's increasing international influence. Therefore, it is urgent to strengthen exchanges between scholars of translation studies and NTP translators so as to deepen the research of national translation theory and practice. As a special form of translation practice, NTP not only promotes the construction of national image and guides the transmission and acceptance of discourse, but also has an indispensable role in the entire translation industry in China.

\section{Conclusion}

Chinese President Xi Jinping stressed that it is necessary to accelerate the development of emerging disciplines and interdisciplinary subjects with important practical significance so that the research in these disciplines will become an important breakthrough point in China's social sciences. This should be the guiding principle for the integration of disciplines for translation studies in China. It is no coincidence that the new-era liberal arts education, a topdown national strategy, also focuses on disciplinary innovation. Translation studies should focus on the perspective of innovation by emphasizing the fusion and integration of multidiscipline, the application of big data, artificial intelligence and other new technical means, as well as the innovation of research paradigms and knowledge production models in liberal arts.

In order to meet the needs of promotion of Chinese culture abroad in the new era, integration of translation studies with communication and other disciplines should be accelerated to complement each other in fostering the intercultural communication ability of translation personnel. Research on the translation and communication of China's EDS should combine interdisciplinary research subjects such as corpus linguistics, corpus translation studies, critical discourse analysis, sociology, and communication. [8]

Since the 1980s, Chinese society has undergone tremendous changes. The Chinese experience, knowledge, ideas, and wisdom that have gradually emerged during this period are increasingly drawing the attention of the outside world, especially the developing countries. In the context of continuous advancement of Promotion of Chinese Culture Abroad as a national strategy, the mission and status of translation have been highlighted, and the current translation studies in China are flourishing. However, China is a big country of translation, but not a powerful country of translation, with limited international influence that can compete with translation studies in the Western world. How to summarize China's experience and knowledge from a global perspective and transform it into an external discourse that can be understood and accepted by international communities, and thereby enhance China's cultural soft power, has become the contemporary responsibilities for scholars and practitioners of translation. Translation studies should be open beyond disciplines with a broad international vision, and take the initiative to assume the social responsibilities and historical missions of the new era in China.

\section{References}

[1] Y. Wu, "A study on the discourse system for global communication with Chinese characteristics: Concept, framework and operation," Foreign Language World, vol. 41, no. 6, pp. 2-11, Dec. 2020. 
[2] F. Yang, "National consciousness and national communication in the construction of national translation ability," Chinese Translators Journal, vol. 42, no. 4, pp. 15-19, Jul. 2021.

[3] A. J. Hu, "International discourse system with Chinese characteristics: Research review and its future exploration," Journal of Beijing International Studies University, vol. 42, no. 5, pp. 3-17, Oct. 2020.

[4] X. Z. Si, "Studies of international discourse system with Chinese characteristics: Retrospect and prospect," Contemporary Foreign Languages Studies, vol. 42, no. 4, pp. 103-112+129, Aug. 2021
[5] B. Shan, "The problem domain of intercultural communication," Intercultural Communication Studies, vol. 1, no. 1, pp. 1-30, Jun. 2020.

[6] D. S. Ren, "National translation program: A conceptual framework," Foreign Languages Research, vol. 36, no. 4, pp. 68-73+112, Aug. 2019.

[7] H. J. Lan, "From reality to theory: Some reflections on national translation activity," Foreign Language and Literature, vol. 36, no. 5 , pp. 112-118, Sep. 2020

[8] W. Zhang, "China's international discourse and its translation / communication (1949-2019): Ideas and methods," Foreign Languages in China, vol. 17, No. 5, pp. 91-99, Sep. 2020. 